\title{
THE LARVA OF LARCASIA PARTITA NAVAS [TRICHOPTERA]
}

by D. G. de JALÓN ${ }^{1}$

The larva of the spanish species Larcasia partita Nav. is described in detail and the difference from other Goeridae larvae are indicated. The French Goeridae larvae key (Grenier, Decamps and Giudicelli 1969) is modified to include this species. The key may be extended to the whole of western Europe, excepting Silo mediterraneus from Sardinia.

\section{La larve de Larcasia partita Nav. (Trichoptera).}

La larve de Larcasia partita Nav. est décrite en détail et les différences avec les autres larves de Goeridae sont indiquées. La clé des larves françaises de Goeridae (Grenier, Decamps et Giudicelli 1969) est modifiée pour inclure l'espèce L. partita; la clé ainsi obtenue peut être étendue à l'ensemble de l'Europe occidentale, à l'exception de Silo mediterraneus de Sardaigne.

The adult stage of Larcasia partita Navás was first described by Navás in 1917. Schmid (1949) studied the collection of Navás and made his own description, accepting the genus Larcasia but not the tribe Larcasini.

Vera (1973) also included Larcasia in his "Claves de determinación de familias y géneros del orden Trichoptera de la régión Paleártica Occidental ».

Some especies of larvae and pupae from the upper reaches of the River Lozoya were reared in the laboratory. Some adults emerged which are in agreement with Schmid's description of Larcasia partita. Schmid (1952) in fact collected Larcasia partita from El Paular, a region through which the River Lozoya flows.

\section{Full-grown larva}

\section{Length $8.10 \mathrm{~mm}$.}

HEAD : Light-brown dorsally, lighter in the flat median area; there is a curved row of round tubercles, with the concavity looking anteriorly.

1. Cátedra de Zoología y Entomología ; Escuela Técnica Superior de Ingenieros de Montes; Universidad Politécnica de Madrid. 

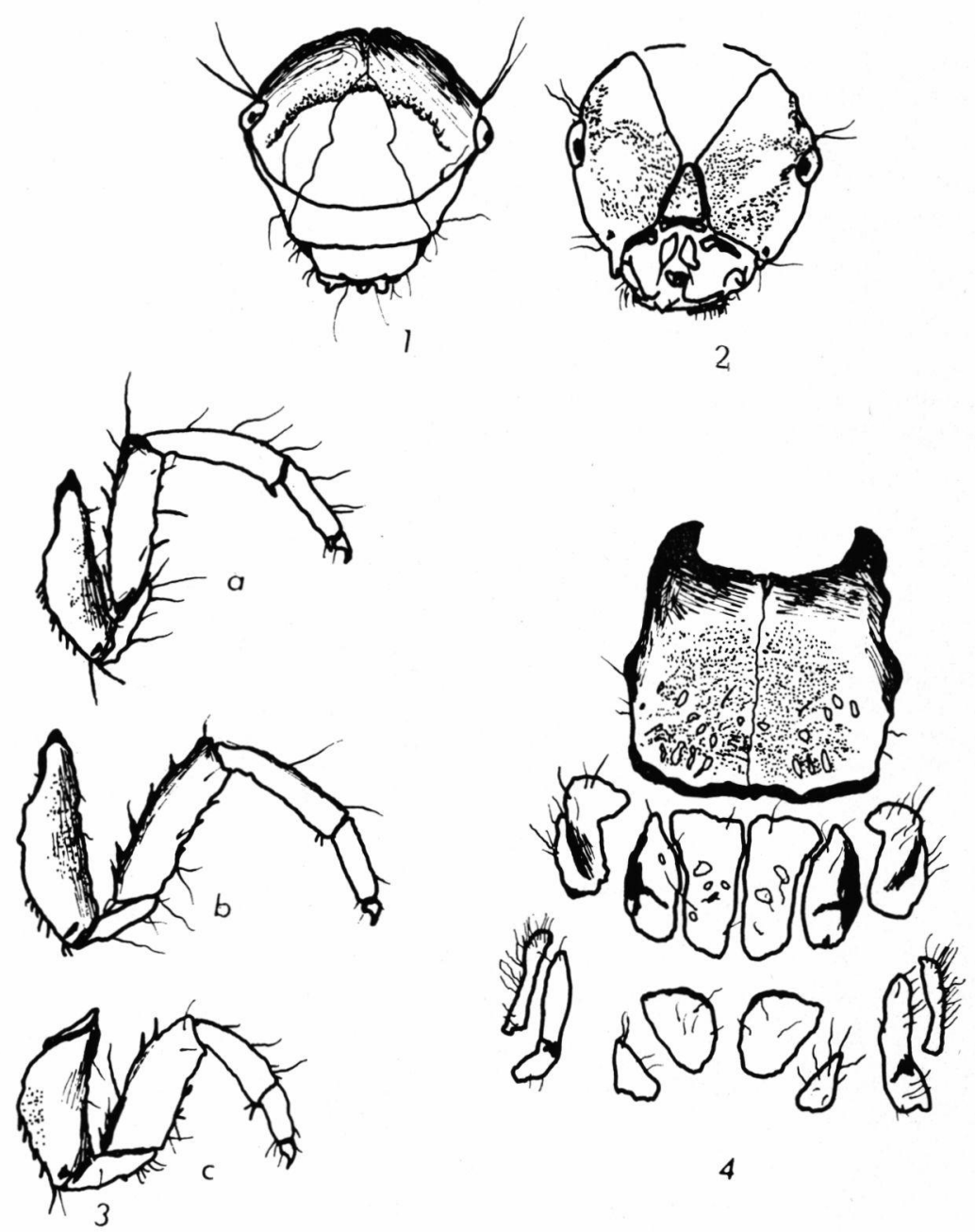

Fig. 1. - Larva of Larcasia partita Nav. - 1. Head dorsal ; 2. Head ventral ; 3. Legs : posterior (a), median (b), anterior (c) ; 4. Dorsal view of thorax.

Ventral surface light yellowish with some dark areas with small pointed tubercles. Gula triangular, dark yellowish with small tubercles, longer than wide, with rounded posterior end; pregula brownyellowish about as wide as the gula.

"Intermediate " and "median anterior margin seta " black and short. Lateral anterior margin setae light and slightly curved.

In the anterior part of the lateral margins there is one pair of long, thick setae and another pair of shorter ones. Two pairs of long 
setae near the eye, posteriorly. Secondary dorsal setae situated in anterior part of frontoclypeus.

Antennae small, anterior to the flat area and ventrally placed (not seen in dorsal view).

Labrum with broadly membranous anterior margin; anterior lateral lobes large, with dense light hairs; median lobe convex, with small hairs.

Mandibles triangular, black at base and red-brown apically; base of other edge with two bristles; inner edge clothed with a brush of hairs.

Maxillae with four segmented palps with brush of outwardly directed hairs. Maxillary lobes very small. Cardo and stipes each bearing a bristle.

Labium covered with small hairs directed anteriorly and the two segmented palps directed posteriorly.
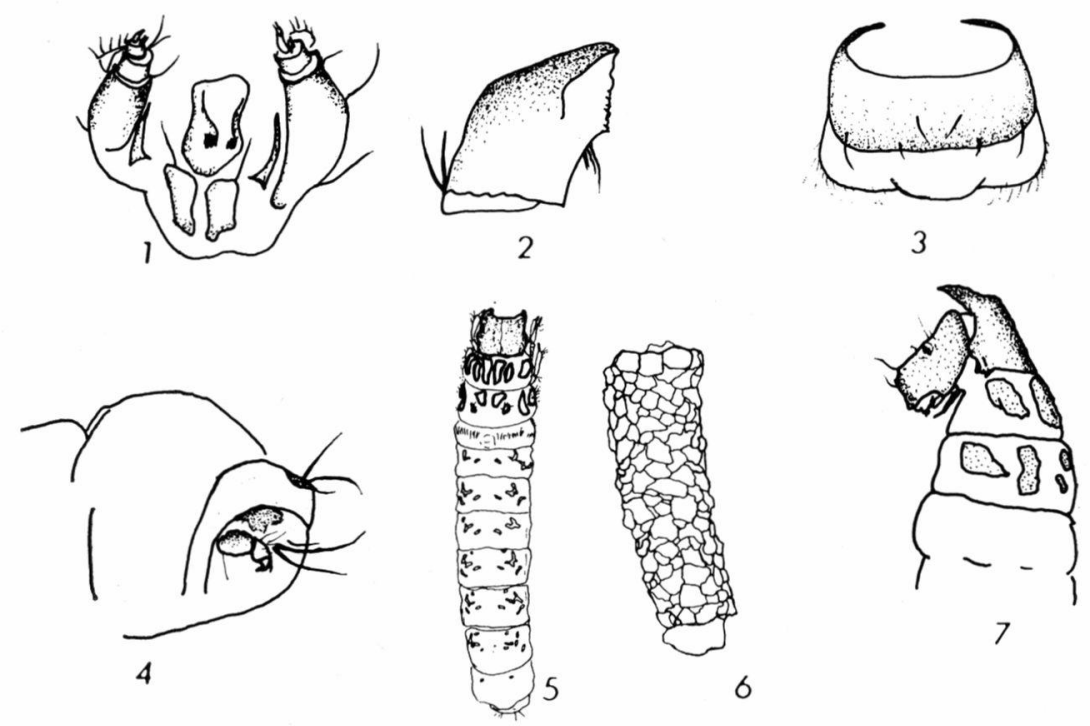

FIg. 2. - Larva of Larcasia partita Nav. - 1. Maxillae and labium ventral view ;

2. Right mandible ; 3 . Labrum ; 4. Posterior segments of abdomen lateral view;

5. Larva, dorsal view ; 6 . Case ; 7 . Half anterior part of larva, dorsal view.

\section{THORAX}

Pronotum : dark-yellowish, covered with small tubercles, with anteriorly projecting angles, into which the head is retracted, as characteristic for the family. Pronotum almost square with lateral margins forming a laterally projecting process; posterior margin of the pronotum very sclerotized, black with two denticles in the extremes. 
In the third posterior part there are several light dots, some long ones and others round. Setae light-brown, small, in posterior part of pronontum.

Mesonotum : dark-yellowish with two pairs of longitudinal sclerites; covered with small, black tubercles and with some brown dots. The lateral sclerites on its outer margin are black coloured. Black setae in all parts of mesonotal sclerites.

Metanotum : with three pairs of dark-brownish sclerites; anteriormedian sclerites situated close together and of trapezoidal shape; the posterior-median sclerites separate and triangular; lateral sclerites long and curved with a lateral concavity with a transverse dark spot in the middle. All the sclerites with numerous setae.

Mesopleuron : shape differs, typically, from other Goeridae : it is neither pointed nor projecting anteriorly to the prothorax.

Meso and Metapleuron : yellowish-brown with a narrow pleural groove and a black spot at distal margin; they are covered by small dark tubercles and setae, but metapleuron more densely covered by setae.

Posternite represented by a small, slightly sclerotized area; horn light yellow, whitish basally, relatively large.

Legs : brown-yellowish, slightly darker in dorsal area, because of small tubercles, mainly on coxae ; ratio of length of legs $76: 100: 95$.

Forelegs more massive than hind ones; femora long; mid-femur thinner and longer than others, tibiae curved and wider distally; tarsi straight, slightly narrower on apex; claws short and massive.

Hind coxae with more setae than others. Row of yellow spines on ventral side of coxae. Femur with a dorsal row of yellow spines and a ventral row of smaller ones directed to the apex; there is also a large and thin spine on middle ventral femur. Setae as figure.

\section{ABDOMEN}

Uniformly wide from segments $2-8$; segment 1 slightly wider, with large dorsal and lateral processes. Lateral line from segment 3 to segment 8 .

Gills with one filament, in dorsal and ventral rows on segments $2-5$; in a pleural row on segment 2 (Table 1). Abdomen basically whitish, dotted brown-reddish, except segment one, which is yellow:

Characteristic white areas, dorsal and ventral. Transverse bands on the ventral side.

Tergite of segment 9 represented by an indistinct dark-brownyellow, hardened, membranous area; median anal seta as long as anterior angle seta. 
TABLE I. $-\mathrm{N}^{\circ}$ and arrangement of gills of Larcasia partita

\begin{tabular}{ccccc}
\hline Segment & Dorsal & \multicolumn{2}{c}{ Pleural } & Ventral \\
\hline 2 & 0 & 0 & 0 & 0 \\
3 & 1 & 0 & 1 & 1 \\
& 1 & 0 & 0 & 1 \\
4 & 1 & 0 & 0 & 1 \\
& 1 & 0 & 0 & 1 \\
5 & $1-0$ & 0 & 0 & 1 \\
& 0 & 0 & 0 & $0-1$ \\
\hline
\end{tabular}

Sclerite " $\mathrm{b}$ " of anal legs honey-yellow, with black dorsal margin.

Sclerite "c" dark-brown-yellowish with two small brown setae. Four pairs of long primary setae.

Claw brown-reddish with a dorsal denticle and small spinule in the basal part.

CASE : 9-11 mm long, made of quarz grains only, smooth, slightly curved, harrower posteriorly with some flat, bigger sand grains on anterior sides, closed by a membrane with a single round hole in the posterior end.

\section{Habitat}

Head-streams and trout-becks where the water is siliceous and very pure with no population from sewage discharges. Lives in the middle of the current where there is a stony or less occasionally in a sandy bottom.

\section{Distribution}

Navàs recorded adults in El Escorial and La Granja. Schmid found adults in El Paular. I have collected larvae and pupae for the lenght of the river Lozoya, above the Pinilla reservoir and in little streams to the south flowing off the Puerto Canencia.

This species is endemic to Spain; there is only two others recorded species of the genus Larcasia which are found in India and Pakistan (Syn. Ashmira elia Mos. and Larcasia assamica Sch.).

\section{Discussion}

Several features differentiate the larva of Larcasia from the Goeridae larvae. Particularly significant are the characters of the mesopleurites which are not anteriorly pointed and the pronotum shape. 
This anatomy data is significant enough to support the inclusion of the genus Larcasia in a special subfamily or in the Larcasia tribe following Navàs (1917).

\section{Inclusion of Larcasia partita in the key to the Goeridae from Wes- tern Europe}

The key to the French Goeridae larvae (Grenier et al. 1968) can be modified to include Larcasia partita. This extended key may thus be considered as a key to the larvae of Western European Goeridae excepting Silo mediterraneus only recorded from Sardinia.

1. Pronotum wider than long; relation length/width between $1 / 2$ and $2 / 3$ (without considering the lateral horns). Mesopleurites pointed and projecting anteriorly ....................

- Pronotum almost as long as wide; relation length/width more than 3/4. Mesopleurites neither pointed nor projecting anteriorly. Mesonotum with two pairs of sclerites. Metanotum with three pairs of sclerites . . . . . . . . . . Larcasia partita (Nav.)

2. See Granier, Décamps and Giudicelli (1969).

\section{ACKNOWLEDGMENTS}

I should like to thank Prof. M.G. de Viedma for reading the manuscript and for his useful comments. Thanks are due to many people who helped in the field; to M.G. Tanago and R. Vera for help with the literature and to Dr. L. Botosanenau and Dr. H. Decamps for confirmation of the adult.

\section{REFERENCES}

Grenier (S.), Decamps (H.) et Giudicelli (J.). 1969. - Les larves de Goeridae de la faune de France. Taxonomie et Ecologie. Annls. Limnol. 5 (2) : 129-161. Navas. 1917. - Broteria. Ser. Zool. 15 : 65-66.

Schmid (F.). 1969. - Les trichoptères de la collection Navas. eos 25 : 412-416.

Schmid (F.). 1952. - Contribution à l'étude des Trichoptères d'Espagne. Pirineos $8: 689$.

VERA (R.). 1973. - Claves de determinación de familias y generos del orden Trichoptera de la región Paleártica Occidental. Servicio de Publicaciones de la Facultad de Ciencias. Universidad Complutense. 